\section{AB0181 EPIDEMIOLOGY STUDY ABOUT OSTEOPOROSIS IN POSTMENOPAUSAL WOMEN ABOUT 1000 CASE}

S Quennesson, E Quennesson, PM Preux, C Scotto Di Fazano, D Coyral, P Vergne, C Bonnet, P Bertin, R Treves. Rheumatology, Universitary Hospital Limoges, Tauxigny, France

\subsection{6/annrheumdis-2001.620}

Background Osteoporosis is a bone disease who concerns above all postmenopausal women. It's characterised by bone loss and associated fractures. In France, in 1995 it's 1\% hospital cost. We realised a transversal study about osteoporosis and risk factors with 1000 women.

Objectives We excluded women with hormonal substitutive treatment and secondary osteoporosis. The study group was randomised. All patients were interviewed about risk factor and bone mineral density was measured by dual energy $\mathrm{X}$ ray. One woman was excluded for myeloma.

Methods We compared risk factor between osteoporosis group and non osteoporosis group determined by densitometry OMS criteria, with student $t$ test or chi2. Finally a multivarious analysis includes all significative risk factor. $(\mathrm{p}<0,05)$.

Results In our study, there was $25 \%$ osteoporotic patients. The univarious analysis find a significant relation between osteoporosis and study level, the age at menopause, thyroid disease, body mass index, calcium intake, milk drink, fresh water consumption, white cheese. The multivarious analysis shows a significant relation between osteoporosis and age (odds ratio $=1,1$ per year), the level study (odds ratio $=0,34$ between; after first grade diploma and no education), Body Mass Index (odds ratio $=$ 0,86 per unity), milk drinks (odds ratio $=0,7$ ).

The discriminant analysis after further adjustment for confounding factors allows to diagnose $67 \%$ of osteoporotic women.

Conclusion In our population, we find some usual risk factor of literature.

The interview is not sufficient to diagnose osteoporosis certainly but allow to purpose bone density. The results of this bone density with clinical information is necessary to start the best treatment.

\section{AB0182 HIP VS CALCANEUS BONE MINERAL DENSITY IN POSTMENOPAUSAL WOMEN}

JA Román-Ivorra, L Abad, C Fernández-Carballido, JJ Alegre-Sancho. Rheumatology, Hospital Universitario Dr. Peset, Valencia, Spain

\subsection{6/annrheumdis-2001.621}

Background Assessment of postmenopausal osteoporosis is usually delayed due to central densitometers' lack in some areas. Peripheral densitometers have been proposed for osteoporosis screening.

Objectives To assess the relationship between bone mineral density (BMD) measurements in post-menopausal women using central (DEXA) and peripheral (PIXI) densitometers.

Methods 81 women, included in a post-menopausal osteoporosis assessment schedule, were consecutively selected for this study. In all women, we collected: 1) an osteoporosis risk factors' questionnaire; 2) measurement of hip BMD, using a DEXA densitometer (NORLAND); and 3) measurement of calcaneus BMD, using the peripheral densitometer PIXI(LUNAR).

Results Osteoporosis risk factors collected: mean age (years) = 63(9.6 sd); mean time since menopause (years) $=15.6(9.2 \mathrm{sd})$; mean body mass index $=28.9(4.5 \mathrm{sd})$; mother's hip fracture $=$ $6.2 \%$; previous Colles fracture $=8.6 \%$; previous vertebral fracture $=6.2 \%$; previous hip fracture $=1.2 \%$; other non-traumatic fractures $=13.6 \%$; calcium intake $<1 \mathrm{~g} / \mathrm{d}=88.9 \%$; sedentarism $=45.7 \%$. Statistical significance was found between absolute BMD values (Pearson's correlation coefficient: $\mathrm{r}=0.501(\mathrm{p}=$ $0.01)$ ), and t-score values (Pearson's correlation coefficient: $\mathrm{r}=$ $0.575(\mathrm{p}=0.01))$ obtained with both densitometers.

Conclusion Peripheral densitometers can be a reliable and suitable choice for postmenopausal osteoporosis screening in primary health centres.

\section{AB0183 CORRELATION BETWEEN THE BONE MINERAL DENSITY AND THE OBESITY IN HEALTHY WOMAN}

NZ Vujasinovic-Stupar, P Vukojevic, NZ Pilipovic. Clinical Department I, Institute of Rheumatology-Belgrade, Belgrade, Yugoslavia

10.1136/annrheumdis-2001.622

\section{Background}

Objectives

Methods In 425 randomly chosen women, bone mineral density (BMD) assessment of lumbar spine (region L2-L4) was done using LUNAR DPXL device. All the subjects included were healthy with negative significant risk factors for osteoporosis. The demographic data of included subjects are: Mean age of women was 47.1 (20-78) yrs; menarche mean age was 13.5 (10-19) yrs; average weight $68.8(45-107) \mathrm{kg}$ and average height $160(147-183) \mathrm{cm}$; mean value of BMI was $25.6(14.8-$ $45.6) \mathrm{kg} / \mathrm{m}^{2}$; mean value of BMD was $1.16(0.701-1.98) \mathrm{g} / \mathrm{ccm}$.

According to BMI the subjects were divided in 4 groups (grade $0=$ normal, grade $1=$ mild obesity, grade $2=$ moderate obesity and $3=$ severe obesity) and the linear correlation test was done between BMD and BMI.

Results The results with correlation coefficient $(\mathrm{R})$ and corresponding $\mathrm{p}$ values are shown in the Table 1 .

\begin{tabular}{llllll}
\multicolumn{5}{l}{ Abstract AB0183 Table 1} & \multicolumn{1}{l}{ Correlation between BMI and BMD } \\
\hline \multicolumn{7}{c}{ BMI $\left(\mathbf{k g} / \mathbf{m}^{2}\right)$} \\
\hline Group $/ \mathbf{N}$ & $0 / 234$ & $1 / 104$ & $11 / 69$ & $111 / 18$ & Total/425 \\
BMD $\left(\mathbf{g} / \mathrm{cm}^{2}\right)$ & $22.4 \pm 1.9$ & $27.0 \pm 1.4$ & $31.3 \pm 1.6$ & $37.3 \pm 1.93$ & $25.6 \pm 4.6$ \\
$\mathbf{R}$ & 0.078 & 0.233 & 0.27 & -0.497 & 0.134 \\
$\mathbf{p}$ & 0.906 & 0.16 & 0.021 & 0.036 & 0.006 \\
\hline
\end{tabular}

Conclusion The significant positive correlation $(p=0,006)$ was observed between lumbar spine BMD and BMI in whole group. In subjects with normal BMI (group 0) and mild obesity such correlation was not present. In subjects with moderate obesity significant positive correlation was observed $(p=0,021)$, while in group representing severe obesity subjects highly significant negative correlation was calculated $(\mathrm{p}=0,036)$.

\section{AB0184 MISDIAGNOSIS OF INSUFFICIENCY FRACTURES IN PATIENTS WITH INFLAMMATORY JOINT DISEASE}

${ }^{1} \mathrm{D}$ Schapira, ${ }^{2} \mathrm{D}$ Militianu, ${ }^{1} \mathrm{Y}$ Braun-Moscovici, ${ }^{1} \mathrm{AM}$ Nahir. ${ }^{1}$ Rheumatology Service;

${ }^{2}$ Department of Diagnostic Radiology, Rambam Medical Center, Haifa, Israel

10.1136/annrheumdis-2001.623 
Background Insufficiency fractures may occur in patients with long-standing inflammatory joint diseases (IJD). Activity of the disease, immobilisation and prolonged corticosteroid treatment are the main predisposing factors. In most cases the fractures are easily diagnosed, in others the diagnosis is delayed, as they may mimic exacerbation of the underlying disease or other pathological conditions.

Objectives To evaluate the clinical profile of patients with initially misdiagnosed insufficiency fractures and to investigate the causes of the diagnostic delay.

Methods The files of 12 patients with IJD who were referred for presumed exacerbation of the rheumatic disease and were subsequently diagnosed as suffering from insufficiency fractures were reviewed and relevant parameters were analysed.

Results Most of the patients were aged (mean 68.5 years) and were suffering from IJD for long periods of time (mean 16.6 years). All of them received prolonged corticosteroid therapy (mean 9.5 years) in doses up to $15 \mathrm{mg}$ prednisone a day). Five patients had previous insufficiency fractures. The new fractures were located in the distal tibia, femoral neck, head of humerus, lesser trochanter of the femur, sacrum, pubic rami, acetabulum and metatarsus. The initial diagnosis was: acute synovitis (8 patients), trochanteric bursitis (1), radiculopathy (1), tendinitis (1) and avascular necrosis of bone (1). The diagnostic delay was one to eight weeks (mean 2.7). In seven patients the correct diagnosis was reached by initial radiographs and in five by bone scintigraphy and CT. Treatment with bed rest, non weight bearing, NSAID (all patients) and calcitonin (7 cases) resulted in partial (8 patients) or complete recovery (4 patients).

Conclusion Insufficiency fractures can mimic disease activity or other musculoskeletal pathological conditions in patients with IJD. Clinician's awareness may prevent unnecessary investigations and therapy.

\section{REFERENCES}

1 Lingg GM, Soltesz I, Kessler S, Dreher R. Insufficiency and stress fractures of the long bones occuring in patients with rheumatoid arthritis and other inflammatory diseases, with a contribution on the possibilities of computed tomography. Eur $J$ Radiol. 1997;26:54-63

2 Alonso-Bartolome P, Martinez-Taboada VM, Blanco $R$, Rodriguez-Valverde V. Insufficiency fractures of the distal tibia and fibula. Semin Arthritis Rheum. 1999;28:413-20

\section{AB0185 EVALUATION OF PHYSICAL CAPACITY AND DISABILITY IN OSTEOPOROTIC WOMEN}

I Lombardi Junior, LM Oliveira, CR Monteiro, YQ Confessor, TL Barros, J Natour. Departamento de Medicina, Universidade Federal de São Paulo, São Paulo, Brasil

\subsection{6/annrheumdis-2001.624}

Background The vertebral osteoporotic fractures result in increased kyphosis angle. This alteration could led to disturbance in physical capacity.

Objectives Our objective was to evaluate the physical capacity and disability in a group of osteoporotic patients.

Methods Fifteen women with osteoporosis and vertebral fracture (G1), 20 women with osteoporosis without vertebral fracture (G2) and 20 normal women (G3) were selected. The variables of physical capacity were measured in the belt conveyor. The patients stayed $4 \mathrm{~min}$ in standing quietly, $4 \mathrm{~min}$ walking at 3 $\mathrm{Km} / \mathrm{h}$ and $10 \mathrm{~min}$ walking at $4 \mathrm{Km} / \mathrm{h}$. It was also applied the questionnary SF-36.
Results Our results showed that women with osteoporosis and vertebral fracture had increased kyphosis angle (median $=60$ degrees) and the G2 was 43.5 degrees and G3 was 37 degrees.

G1 showed oxygen consumption (VO2 (Kg)), METS and energy expenditure $(\mathrm{Kcal} / \mathrm{h})$ in standing quietly bigger than $\mathrm{G} 2$ (G1 vs. G2, $p=0.016 ; p=0.017$ and $p=0.02$, respectively). There wasn't significant difference in the energy expenditure during the walking between three groups.

The energy expenditure during walking at $3 \mathrm{Km} / \mathrm{h}$ and at 4 $\mathrm{Km} / \mathrm{h}$, showed correlation with thoracic kyphosis in $\mathrm{G} 1$ ( $\mathrm{p}=$ 0.01 and $p=0.017$, respectively).

It wasn ' $t$ find difference in SF-36 between three groups.

Conclusion Energy expenditure showed correlation with the angle of thoracic kyphosis. Patients with or without osteoporosis had the same energy expenditure during the walking. The SF-36 score was similar between three groups.

\section{AB0186 CHANGES IN BONE TURNOVER MARKERS AND VITAMIN D RECEPTOR (VDR) GENOTYPE DURING GLUCOCORTICOID THERAPY}

${ }^{1} \mathrm{M}$ Gantes, ${ }^{1} \mathrm{~A}$ Arteaga, ${ }^{2} \mathrm{Y}$ Barrios, ${ }^{1} \mathrm{I}$ Ferraz, ${ }^{1} \mathrm{~A}$ Alvarez, ${ }^{1} \mathrm{~B}$ Rodríguez-Lozano, ${ }^{1} \mathrm{D}$ Batista, ${ }^{1} \mathrm{E}$ Trujillo, ${ }^{1} \mathrm{~T}$ González. ${ }^{1}$ Rheumatology; ${ }^{2}$ Research Unit, Hospital Universitario de Canarias, La Laguna, Spain

10.1136/annrheumdis-2001.625

Background Adverse effects of glucocorticoids (GCT) upon the skeleton and markers of bone turnover have been documented but the mechanisms remain unclear.

Objectives To test of early changes in markers of bone turnover for three months of GCT and the influence of VDR.

Methods In fifty three patients (age 41,7 SD 12,6) with inflammatory diseases who received a dose greater than $5 \mathrm{mg}$ of prednisone or equivalent (mean dose 1,9 g) for 3 months, the serum levels of parathyroid hormone (PTHi), 25-dihydroxyvitamin D, (Vit D), osteocalcin, alkaline phosphatase, and urine ratios of calcium/creatinine and deoxypyridinoline/creatinine, were determined baseline and 3 months after GCT. VDR genotypes were determined by PCR to demonstrate the presence (b) or absence (B) of a restriction target for Bsm I, in intron 7.

Results The patients with high baseline levels of PTHi showing lower levels of baseline VitD, ( $p=0,003)$ and 3 months after of GCT the patients with lower levels of PTH have the higher levels of Vit D, $(p=0,001, r=0,54)$. There were no significant differences in biochemical markers of bone remodelling between the three genotypes: $\mathrm{bb}, \mathrm{BB}$, and $\mathrm{Bb}$ VDR before and 3 months after GCT.

Conclusion These preliminary results suggest not effect of VDR genotype in the changes of the biochemical markers of bone remodelling for glucocorticoid therapy.

\section{AB0187 PERCUTANEOUS VERTEBROPLASTY IN RHEUMATOLOGY}

MC García Gómez, C Galisteo, N Navarro, M Castellanos, C Alegre, M Rovira, J Serra, LL Mebarak. Rheumatology, Hospital Malaties Reumàtiques, Barcelona, Spain

10.1136/annrheumdis-2001.626

\section{Background}

Objectives The percutaneous vertebroplasty (PVP) consists in the percutaneous injection of a biomaterial, plimethylmethacrylate, inside of vertebral body, with the idea of consolidating the vertebral body and to relieve the pain. It is indicated in the treatment 